\title{
Wenn Aktien
} in den Keller rauschen

Risikomanagement. 11. September, Lehman-Pleite, Corona: Die Welt hat den nächsten Börsencrash. Zwar gab es seit Anfang März zwischendurch auch kurze Phasen des Anstiegs, aber von den Höchstständen Anfang 2020 sind die Kurse weit entfernt. Was tun?

AUTORIN: BETTINA BLASS
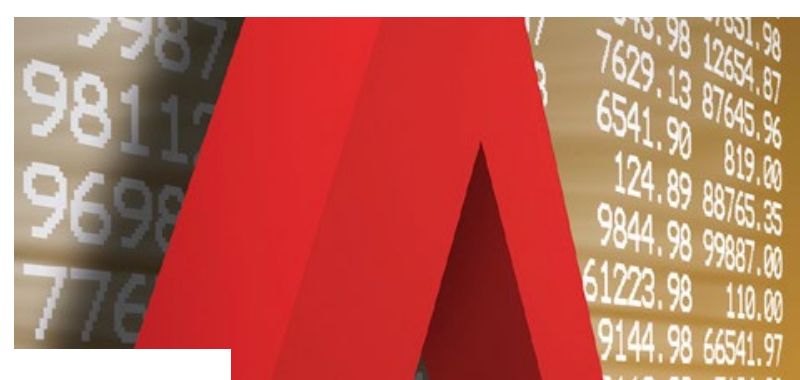

91.144.98 6654.97 1112.9977 .194 .98

„Unvorhersehbare Ereignisse haben immer auch Auswirkungen auf die Börse“, sagt Stefanie Kühn, diplomierte Wirtschaftsingenieurin und zertifizierte Finanzplanerin. „Das trifft selbst Anleger, die optimal aufgestellt sind." Oft stehen abstürzende Wertpapierkurse in Zusammenhang mit einer Katastrophe: Der 11. September 2001 war so ein Tag. Damals waren bei einem Terroranschlag Flugzeuge in die Türme des World Trade Centers in New York geflogen. Ein anderes Beispiel: die LehmanPleite 2008, die der Beginn der Finanzkrise war. 2020 ist es das neuartige Coronavirus, an dem Menschen in aller Welt sterben und das auch die Weltwirtschaft in die Knie zwingt - und die Aktienkurse.

\section{AM BESTEN AUSSITZEN}

"Solch globalen Unruhen kann man sich nicht entziehen", sagt Finanzcoach Stefanie Kühn. Das sei eben das Marktrisiko. Grundsätzlich rät sie darum dazu, „die Aktienquote auf maximal 40 Prozent zu beschränken“. Außerdem sollte man den Aktien-, Fonds- und ETF-Kauf eher langfristig sehen. Nur dann kann man Kursschwankungen ausgleichen.

Einen Verlust machen Anleger übrigens erst dann, wenn sie für Wertpapiere mehr bezahlt haben, als sie beim Verkauf erzielen. Heißt: „Wer jetzt verkauft, wird ein Verlustgeschäft machen.

Darum sollte man das nur dann tun, wenn man dringend Geld benötigt", so Kühn.

WER JETZT
VERKAUFT,
WIRD
VERLUSTE
MACHEN

\section{GÜNSTIGER EINSTIEG}

Wer dagegen auf das Geld verzichten kann, sollte es besser liegen lassen. Wirtschaftsexperten wie Stefanie Kühn gehen zwar davon aus, dass die nächsten Monate auch an der Börse nicht einfach werden. „Aber irgendwann werden 
die Aktienkurse wieder steigen. Spätestens dann sollte man sogar überlegen, einzusteigen oder die Wertpapierquote zu erhöhen. Denn so günstig kann man selten an der Börse einkaufen", rät sie. Allerdings kann niemand sagen, wann der optimale Zeitpunkt ist, mit dem Wertpapierkauf zu beginnen: Die Kurse könnten durchaus noch weiter fallen. Eine alte Börsenregel sagt: Never catch a falling knife - also greife niemals in ein fallendes Messer.

\section{SPARPLAN PROFITIERT}

Um das Risiko auch für die Zukunft so gering wie möglich zu halten, sind übrigens Fonds- oder ETF-Sparpläne eine gute Lösung: „Dabei investiert man jeden Monat einen feste Summe im Wertpapiere“, erklärt Kühn. „In schlechten Zeiten wie im Moment profitiert man dann automatisch, weil der Anleger mehr für sein Geld bekommt. In der Fachsprache nennt man das: vom ,cost average‘ oder Durchschnittskosteneffekt profitieren“, so Kühn. „Außer-

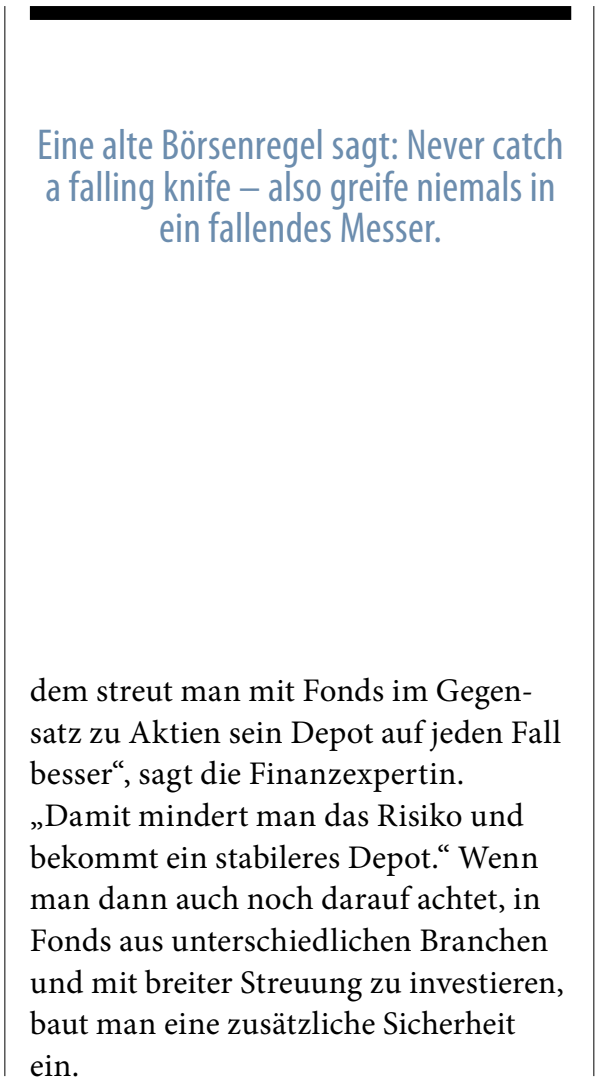
ein.

\section{Hier steht eine Anzeige.}

\section{Springer}

